OPEN ACCESS

Edited by:

Ovidiu Constantin Baltatu,

Camilo Castelo Branco University,

Brazil

Reviewed by:

Christopher J. Madden,

Oregon Health \& Science University,

USA

Elahu Gosney Sustarsic, University of Copenhagen, Denmark

*Correspondence: Labros S. Sidossis lasidoss@utmb.edu

Specialty section: This article was submitted to Integrative Physiology, a section of the journal

Frontiers in Physiology

Received: 24 December 2015 Accepted: 23 March 2016

Published: 19 April 2016

Citation:

Chondronikola M, Volpi E, Børsheim E, Chao T, Porter C, Annamalai $P$, Yfanti $C$, Labbe $S M$, Hurren NM, Malagaris I, Cesani F and Sidossis LS (2016) Brown Adipose

Tissue Is Linked to a Distinct Thermoregulatory Response to Mild Cold in People. Front. Physiol. 7:129. doi: 10.3389/fphys.2016.00129

\section{Brown Adipose Tissue Is Linked to a Distinct Thermoregulatory Response to Mild Cold in People}

\author{
Maria Chondronikola 1,2,3,4, Elena Volpi ${ }^{3,5,6,7}$, Elisabet Børsheim ${ }^{1,8}$, Tony Chao 1,2,3, \\ Craig Porter ${ }^{1,8}$, Palam Annamalai ${ }^{9}$, Christina Yfanti ${ }^{1,6}$, Sebastien M. Labbe ${ }^{10}$, \\ Nicholas M. Hurren ${ }^{1,8}$, Ioannis Malagaris ${ }^{1,2,3}$, Fernardo Cesani ${ }^{11}$ and \\ Labros S. Sidossis ${ }^{1,3,4,5,6,7,8 *}$
}

\begin{abstract}
${ }^{1}$ Metabolism Unit, Shriners Hospitals for Children-Galveston, TX, USA, ${ }^{2}$ Department of Preventive Medicine and Community Health, University of Texas Medical Branch, Galveston, TX, USA, ${ }^{3}$ Division of Rehabilitation Sciences, Department of Nutrition and Metabolism, University of Texas Medical Branch, Galveston, TX, USA, ${ }^{4}$ Department of Nutrition and Dietetics, Harokopio University of Athens, Greece, ${ }^{5}$ Institute for Translational Sciences, University of Texas Medical Branch, Galveston, TX, USA,

${ }^{6}$ Sealy Center on Aging, University of Texas Medical Branch, Galveston, TX, USA, ${ }^{7}$ Department of Internal Medicine, University of Texas Medical Branch, Galveston, TX, USA, ${ }^{8}$ Department of Surgery, University of Texas Medical Branch, Galveston, TX, USA, ${ }^{9}$ Department of Interventional Radiology, University of Texas Medical Branch, Galveston, TX, USA, ${ }^{10}$ Quebec Heart and Lung Research Institute Centre, Quebec, QC, Canada, ${ }^{11}$ Department of Nuclear Medicine, University of Texas Medical Branch, Galveston, TX, USA
\end{abstract}

Brown adipose tissue (BAT) plays an important role in thermoregulation in rodents. Its role in temperature homeostasis in people is less studied. To this end, we recruited 18 men [8 subjects with no/minimal BAT activity (BAT-) and 10 with pronounced BAT activity (BAT+)]. Each volunteer participated in a $6 \mathrm{~h}$, individualized, non-shivering cold exposure protocol. BAT was quantified using positron emission tomography/computed tomography. Body core and skin temperatures were measured using a telemetric pill and wireless thermistors, respectively. Core body temperature decreased during cold exposure in the BAT - group only $\left(-0.34^{\circ} \mathrm{C}, 95 \% \mathrm{Cl}\right.$ : -0.6 to $\left.-0.1, p=0.03\right)$, while the cold-induced change in core temperature was significantly different between BAT+ and BAT - subjects (BAT+ vs. BAT-, $\left.0.43^{\circ} \mathrm{C}, 95 \% \mathrm{Cl}: 0.20-0.65, p=0.0014\right)$. BAT volume was associated with the cold-induced change in core temperature $(p=0.01)$ even after adjustment for age and adiposity. Compared to the BAT- group, BAT+ subjects tolerated a lower ambient temperature (BAT-: $20.6 \pm 0.3^{\circ} \mathrm{C}$ vs. BAT+: $19.8 \pm 0.3^{\circ} \mathrm{C}$, $p=0.035)$ without shivering. The cold-induced change in core temperature $(r=0.79$, $p=0.001)$ and supraclavicular temperature $(r=0.58, p=0.014)$ correlated with BAT volume, suggesting that these non-invasive measures can be potentially used as surrogate markers of BAT when other methods to detect BAT are not available or their use is not warranted. These results demonstrate a physiologically significant role for BAT in thermoregulation in people. This trial has been registered with Clinaltrials.gov: NCT01791114 (https://clinicaltrials.gov/ct2/show/NCT01791114).

Keywords: brown adipose tissue, thermoregulation, body core temperature, supraclavicular skin temperature, cold exposure 


\section{INTRODUCTION}

Thermoregulation is a vital homeostatic mechanism maintaining the core body temperature within a relatively narrow range in the face of large fluctuations in ambient temperature (Mekjavic and Eiken, 2006). Deviation from this normal range may indicate the presence of a pathological condition and can be lethal in extreme cases. Brown adipose tissue (BAT) has been shown to be the primary thermoregulatory tissue during non-shivering cold exposure (CE) in mammals (Cannon and Nedergaard, 2004). Its thermogenic properties are attributable to its numerous mitochondria, which contain high amounts of the uncoupling protein 1 (UCP1, also known as thermogenin) (Nedergaard et al., 2001). UCP1 uncouples oxidative phosphorylation, resulting in heat production (thermogenesis).

BAT has only recently been identified in adults (Nedergaard et al., 2007; Cypess et al., 2009; van Marken Lichtenbelt et al., 2009; Virtanen et al., 2009) and thus its thermoregulatory role in people remains unclear. Historically, BAT has been proposed to play a role in thermoregulation in infants, who have copious amounts of BAT (Ito and Kuroshima, 1967), apparently because they lack the ability to shiver (Silverman et al., 1964; Dawkins and Scopes, 1965). Acute CE (2-6 h) activates BAT (van Marken Lichtenbelt et al., 2009; Virtanen et al., 2009; Ouellet et al., 2012; Chondronikola et al., 2014), while chronic CE (10 days to 6 weeks) can further increase the detectable BAT activity in lean, obese, and patients with type 2 diabetes (Yoneshiro et al., 2013; van der Lans et al., 2013; Blondin et al., 2014; Lee et al., 2014; Hanssen et al., 2015a,b). Consistent with results of the classic study by Davis (1961) more than 50 years earlier, it has been recently reported that chronic CE not only increases BAT activity, but also increases thermal comfort and trunk skin temperature (van der Lans et al., 2013; Hanssen et al., 2015a,b). However, the magnitude of change in the previously mentioned responses was not correlated with BAT. Blondin et al. (2014) also reported an increase in BAT activity after 4-week cold acclimation, but no difference in the thermal responses of subjects before and after acclimation. Therefore, the physiological significance of BAT in human thermoregulation remains unclear.

Considering the lack of evidence on the thermoregulatory role of human BAT, we conducted a study to determine if there is a physiologically significant role of BAT in temperature homeostasis in people. We studied 18 men with significant BAT activity (BAT $+; n=10$ ) or without/minimal BAT activity (BAT-; $n=8$ ), using an individualized, $6 \mathrm{~h}$, non-shivering $\mathrm{CE}$ protocol. We found that the presence of BAT is associated with higher tolerance to cold, supported by the findings of higher core body temperature during $\mathrm{CE}$ noted in subjects with high amounts of BAT, while the BAT+ group was able to tolerate a lower ambient temperature without shivering. These results support a physiologically significant role for human BAT in thermoregulation.

\section{MATERIALS AND METHODS}

\section{Participants}

Twenty men enrolled in this study. Only healthy subjects qualified to participate. Informed written consent was obtained from all participants in accordance with the Declaration of Helsinki; the University of Texas Medical Branch Institutional Review Board and the Institute for Translational Sciences (ITS) Scientific Review Committee approved the study protocol. From the subjects enrolled in the study, one participant dropped out, while body temperature data were not recorded for one participant due to equipment failure. Results from 18 participants were analyzed (Figure 1). This trial has been registered with Clinaltrials.gov: NCT01791114 https://clinicaltrials.gov/ct2/show/NCT01791114).

\section{Experimental Protocol}

Three days prior to the study, participants were asked to follow their regular weight-maintaining diet and to refrain from any excessive physical activity, alcohol, and caffeine consumption. The evening before the study, the subjects were admitted to the ITS Clinical Research Center and offered a standardized meal. Subjects fasted and rested in bed overnight, wearing standardized clothing (a T-shirt and a pair of shorts), and covered with a blanket. The temperature of the room was $23-24^{\circ} \mathrm{C}$.

The following morning a $6 \mathrm{~h}$, individualized, $\mathrm{CE}$ protocol was employed to maximally induce non-shivering thermogenesis. In addition to the standardized clothing, subjects wore garments cooled by liquid circulation (Cool Flow ${ }^{\circledR}$ vest and blanket and Arctic Chiller cooling system, Polar Products Inc., Stow, OH) and laid supine. The temperatures of the cooling garments and the room were initially set at approximately $19-20^{\circ} \mathrm{C}$ and were decreased by $1^{\circ} \mathrm{C}$ approximately every $30 \mathrm{~min}$ until subjects reported shivering. Then, the cooling garment and ambient temperatures were increased by $1^{\circ} \mathrm{C}$ and adjusted as needed to prevent shivering. Additionally, we visually inspected the subjects for shivering.

\section{Temperature Measurements and Thermal Sensation}

Wireless probes (iButtons, Maxim, Dallas, TX) were used to measure the skin temperature of the participants, the room, and the water circulating through the cooling garments. The probes were placed using adhesive tape in 14 locations of the body (forehead, neck, right scapula, left upper chest, right arm in the upper location, left arm in the lower location, left hand, right abdomen, left paravertebral area, right anterior thigh, left posterior thigh, right shin, left calf, and right instep) according to a standard protocol (ISO9886, 2004). The average skin temperature was calculated as the average of those 14 probes (ISO9886, 2004). One additional probe was placed on the skin area over the left supraclavicular adipose tissue depot (where BAT is usually localized). Temperature recording using the wireless thermistors failed in two participants. 


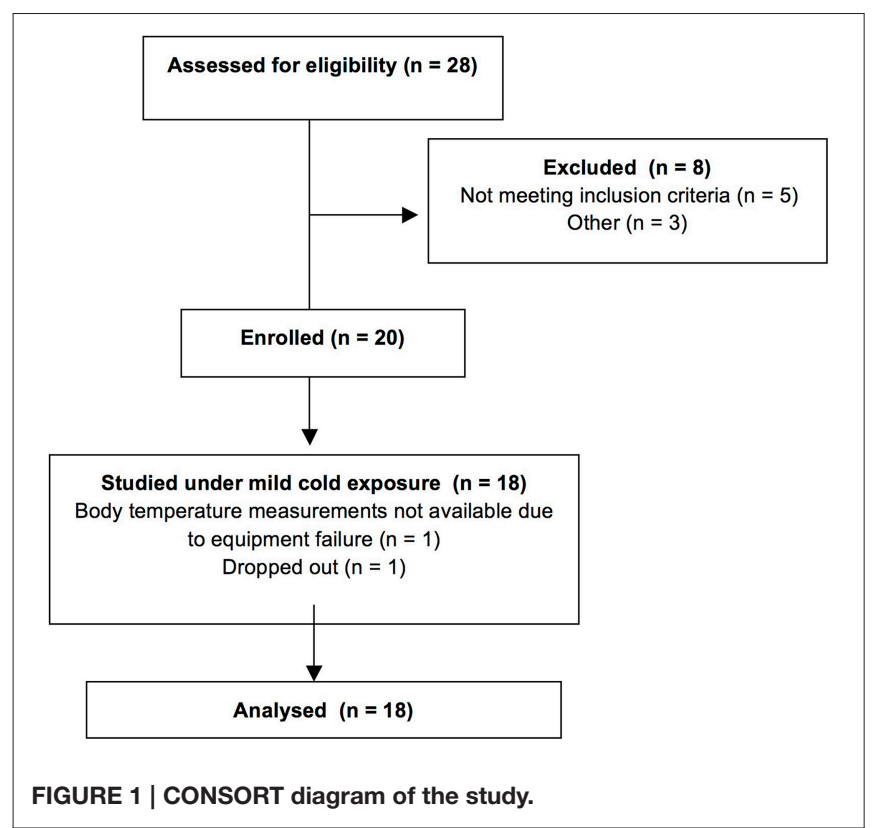

The trunk temperature was calculated as the average of the skin temperatures recorded by the probes placed in the right scapula, the paravertebral area, the abdomen, and the chest, while the distal temperature was calculated as the average skin temperatures of the probes placed on the instep and hand (Wijers et al., 2011). The temperature gradient between the foot and the ambient temperature was used as an index of vasoconstriction and skin perfusion (Ruiz et al., 1979). Thermal sensation was assessed using a visual analog scale of the American Society of Heating, Refrigerating, and Air-Conditioning Engineers (de Dear et al., 1998; de Deara and Brager, 2002). Core temperatures were measured using a telemetric pill (Core-Temp, HQ Inc., Palmeto, $\mathrm{FL}$ ) that was ingested by 14 participants (6 BAT- and $8 \mathrm{BAT}+$ ).

\section{Positron Emission Tomography/Computerized Tomography (PET/CT)}

After $5 \mathrm{~h}$ of $\mathrm{CE}$, subjects were given a bolus injection of 185 $\mathrm{MBq}$ of 2-deoxy-2-( $\left.{ }^{18} \mathrm{~F}\right)$ fluoro-D-glucose $\left({ }^{18} \mathrm{~F}\right.$-FDG). One hour later, a PET/CT (General Electric Medical Systems, Milwaukee, WI) scan was performed to assess BAT volume $(\mathrm{ml})$ and mean standardized uptake value (SUV; g/ml). We assessed the PET/CT scans for ${ }^{18}$ F-FDG BAT using the following criteria: (a) ${ }^{18} \mathrm{~F}-\mathrm{FDG}$ uptake was evident in the cervical/supraclavicular, mediastinal, paravertebral, and/or perirenal areas; (b) ${ }^{18}$ F-FDG uptake had a mean SUV of 1.5 or greater (an indicator of ${ }^{18}$ F-FDG uptake intensity); and (c) the tissue corresponded to the density of adipose tissue on CT ( -190 to -30 Hounsfield units). The mean SUVs for each identified deposit were determined using commercial fusion software (MIM software; MIMvista Corp., Cleveland, $\mathrm{OH}$ ). The volume of ${ }^{18}$ F-FDG BAT was quantified by autocontouring each identified individual BAT deposit (with a $\mathrm{SUV} \geq 1.5$ ).
TABLE 1 | Subject characteristics.

\begin{tabular}{llll}
\hline Parameters & All $(\boldsymbol{n}=\mathbf{1 8})$ & BAT- $(\boldsymbol{n}=\mathbf{8})$ & BAT+ $(\boldsymbol{n}=\mathbf{1 0})$ \\
\hline Age $(\mathrm{y})$ & $46.9 \pm 18.1$ & $57.5 \pm 16.2$ & $38.4 \pm 15.3^{\star}$ \\
$\mathrm{BMl}\left(\mathrm{kg} / \mathrm{m}^{2}\right)$ & $29.5 \pm 4.6$ & $31.0 \pm 3.2$ & $28.2 \pm 5.4$ \\
BSA $\left(\mathrm{m}^{2}\right)$ & $2.05 \pm 0.15$ & $2.05 \pm 0.12$ & $2.05 \pm 0.19$ \\
Lean Body Mass $(\mathrm{kg})$ & $61.0 \pm 8.0$ & $59.6 \pm 5.6$ & $62.2 \pm 9.7$ \\
Body Fat $(\%)$ & $31.7 \pm 9.3$ & $36.0 \pm 3.4$ & $28.2 \pm 11.1$ \\
BAT volume $(\mathrm{ml})$ & $38.7 \pm 44.2$ & $3.7 \pm 4.7$ & $66.9 \pm 41.3^{\star \star *}$ \\
BAT mean SUV $(\mathrm{g} / \mathrm{ml})$ & $1.75 \pm 0.91$ & $1.03 \pm 0.73$ & $2.34 \pm 0.57^{\star \star *}$ \\
\hline
\end{tabular}

Data are mean standard deviations. ${ }^{*} p=0.02{ }^{* * *} p=0.001$ by Student's $t$-test between $B A T+$ and BAT - subjects. BMI, body mass index; BAT, brown adipose tissue; BAT+, detectable BAT; BAT-, no detectable BAT; BSA: SUV, standard uptake value.

\section{Body Composition}

We used Dual X-Ray Absorptiometry to evaluate the lean body mass and total body fat mass of the participants (Hologic model QDR-4500W, Hologic Inc., Bedford, MA).

\section{Statistical Analysis}

All results are presented as means \pm standard deviations. BAT + and BAT - subjects were compared using Student's $t$-test (for normally distributed data) or the Mann Whitney test (for not normally distributed data). The one sample $t$-test was used to compare if the cold-induced change in body core and supraclavicular temperatures was different from 0 in BAT + and BAT - participants. Paired $t$-test (for normally distributed data) or Wilcoxon singed-rank test (for not normally distributed data) were used to compare CE and TN conditions. The Pearson's $\mathrm{r}$ was used to evaluate the correlation between BAT or muscle activity with body temperatures. A multiple linear regression modeled the relation between each outcome and BAT volume, while adjusting for the potentially prognostic covariates age and percent fat. BAT volume was log (base 10) transformed for better centering and interpretation. Statistical analyses were performed using Graph Pad version 5 for Mac OS X (Graph Pad Software, Inc. La Jolla, CA) and SPSS Version 20 for Mac statistical software (IBM Inc., Armonk, NY). All statistical tests assumed a 95\% level of confidence.

\section{RESULTS}

\section{Subject Characteristics}

The study sample consisted of 18 men (Table 1). Participants were divided into two groups: 10 subjects with significant BAT activity $(\mathrm{BAT}+)$ and 8 subjects with no/minimal BAT activity (BAT-). The two groups were significantly different, by design, in BAT volume [63.1 ml, 95\% confidence interval (CI): $31.8-94.4, p=0.001]$ and activity $(1.3 \mathrm{~g} / \mathrm{ml}, 95 \% \mathrm{CI}$ : $0.7-2.0, p=0.001)$. Moreover, the participants in the BATgroup were older (19.1 years, 95\% CI: $3-35, p=0.02)$ and tended to have higher body fat content $(7.8 \%, 95 \%$ CI: -0.9 to $16.5, p=0.08)$ compared to the BAT+ group. 
A

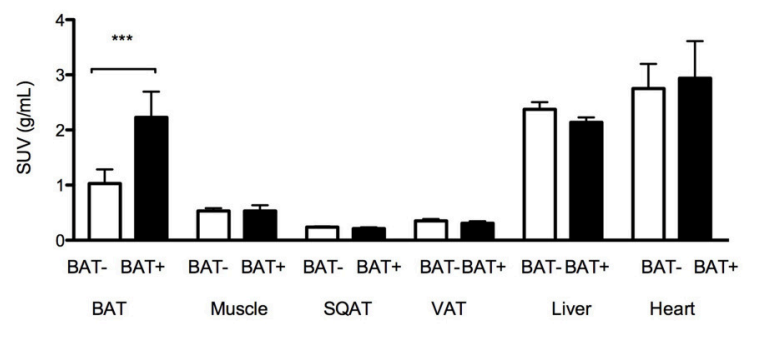

C

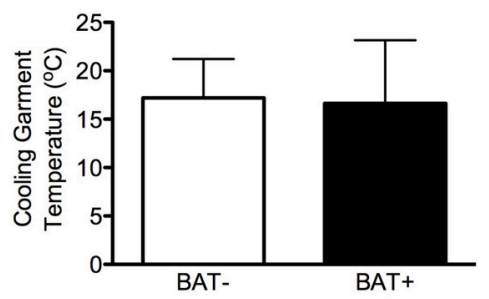

B

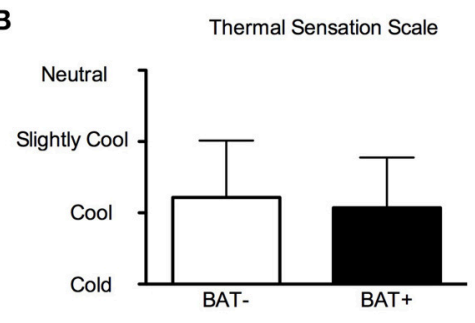

D

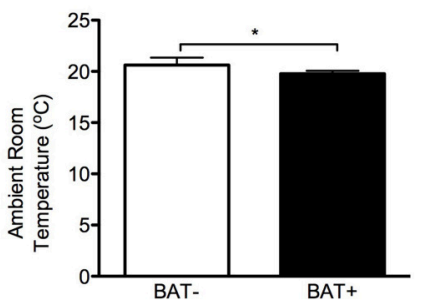

FIGURE 2 | Brown adipose tissue (BAT), cold exposure (CE) tolerance, and thermal sensation. (A) Mean standardized uptake value (SUV) for glucose in various tissues at $6 \mathrm{~h}$ of CE. SQAT, subcutaneous adipose tissue; VAT, visceral adipose tissue. (B) Thermal sensation in subjects with detectable BAT (BAT+) and without detectable BAT (BAT-) at $5 \mathrm{~h}$ of CE. (C) Cooling garments temperature in BAT+ and BAT- subjects at $5 \mathrm{~h}$ of CE. (D) Ambient room temperature in BAT+ and BAT - subjects at $5 \mathrm{~h}$ of CE. The data are means and standard deviations. ${ }^{*} p=0.035$ using Mann-Whitney test and ${ }^{* * *} p=0.001$ using paired $t$-test.

\section{Effect of BAT Activation on Tolerance to CE and Thermal Sensation}

The study participants followed an individualized CE protocol to maximally induce non-shivering thermogenesis (i.e., ambient and garment water temperatures were adjusted to the lowest level tolerated by each subject without shivering). As expected, the results of the ${ }^{18} \mathrm{~F}-\mathrm{FDG}-\mathrm{PET} / \mathrm{CT}$ analyses support that the BAT + group demonstrated higher BAT metabolic activity compared to BAT - subjects. No significant differences were observed in the other tissues between BAT + and BAT - subjects (Figure 2A).

$\mathrm{BAT}+$ and BAT - subjects reported comparable levels of thermal sensation during CE (Figure 2B). Subjectively, both groups reported "feeling cool" during the study. According to the study protocol, the temperature of the room, and the cooling garments was titrated to the lower tolerable level without shivering. The temperature of the water circulating in the cooling garments was also similar in the two groups (Figure 2C). However, the room temperature was slightly lower in the BAT+ group (BAT-: $20.6 \pm 0.3^{\circ} \mathrm{C}$ vs. BAT $+: 19.8 \pm 0.3^{\circ} \mathrm{C}, p=0.035$, Figure 2D). These findings suggest that the subjects in the BAT+ group had a higher tolerance to cold.

\section{Effect of BAT Activation on Body Core Temperature}

Core body temperature decreased after $5 \mathrm{~h}$ of $\mathrm{CE}$ only in the BAT - group $\left(-0.34^{\circ} \mathrm{C}, 95 \% \mathrm{CI}:-0.6\right.$ to $-0.1, p=$ 0.03) (Figure 3A). Interestingly, the cold-induced change in core temperature was significantly different between BAT + and BAT - subjects $\left(0.43^{\circ} \mathrm{C}, 95 \% \mathrm{CI}: 0.20-0.65, p=0.0014\right)$, while BAT volume significantly correlated with cold-induced change in core temperature $(r=0.79, p=0.001$, Figure $3 \mathbf{B})$. No correlation
TABLE 2 | Muscle metabolic activity and body temperatures.

\section{Parameters}

Change in core temperature $\left({ }^{\circ} \mathrm{C}\right)$

$r=-0.324$

$p=0.259$

Change in supraclavicular skin temperature $\left({ }^{\circ} \mathrm{C}\right)$

$r=-0.412$

$p=0.101$

Change in trunk temperature $\left({ }^{\circ} \mathrm{C}\right)$

$r=0.103$

$p=0.685$

The correlation coefficients were calculated using Pearson's r.

was noted between muscle activity (measured as the mean skeletal muscle SUV for glucose during CE in the $m$. pectoralis major and $m$. vastus lateralis) and change in core temperature at the $5 \mathrm{~h}$ of CE (Table 2) or any other time point (data not shown).

BAT activity has been inversely associated with age (Cypess et al., 2009; Yoneshiro et al., 2011) and adiposity (Saito et al., 2009; van Marken Lichtenbelt et al., 2009). To account for potential confounding, we performed multiple linear regression analysis adjusting for age and adiposity (Table 3). After adjustment for age and adiposity, BAT volume was significantly associated with higher body core temperature $(p=0.01)$ after $5 \mathrm{~h}$ of CE. Collectively, these results suggest that cold-stimulated BAT activity can be involved in core temperature regulation in people.

\section{Effect of BAT Activation on Skin Temperature}

We further hypothesized that, should BAT have a thermoregulatory role in people, the skin temperature of the BAT+ subjects would have a different response to cold than that of BAT - subjects, especially in areas adjacent to the 
A
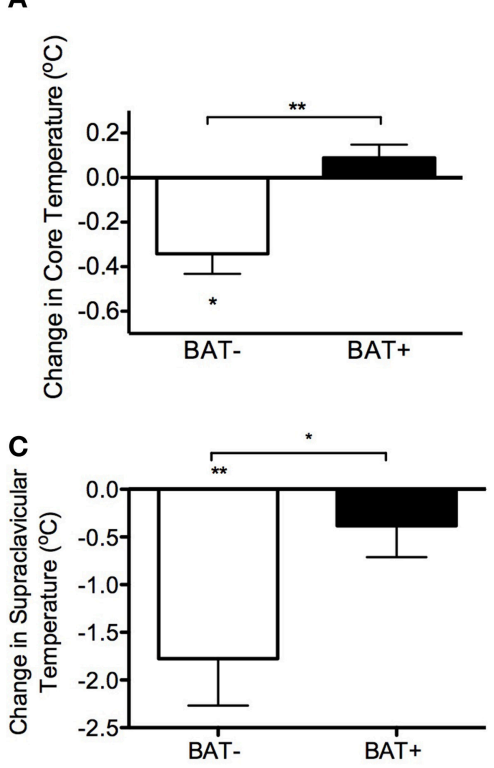

B

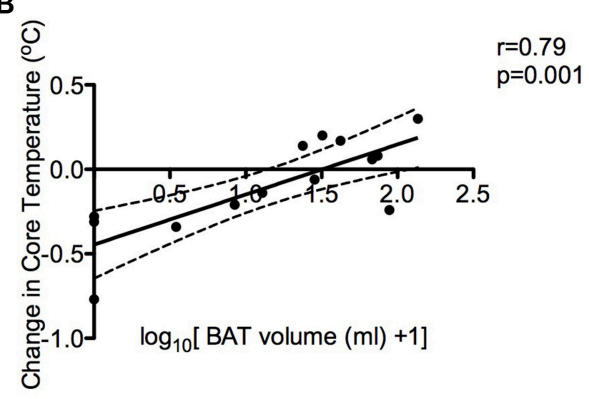

D

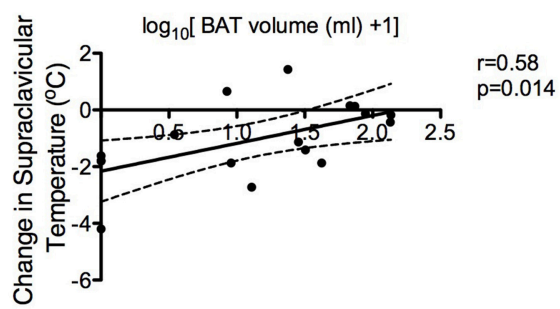

FIGURE 3 | Brown adipose tissue (BAT) and body temperature. (A) Cold-induced change in core temperature in subjects with detectable BAT (BAT+) and without detectable BAT (BAT-). ${ }^{* *} p=0.0014$ using Student's $t$-test, ${ }^{*} p=0.03$ using one sample $t$-test. (B) Correlation of BAT volume with the change in body core temperature using Pearson's r. (C) Cold-induced change in supraclavicular skin temperature in BAT+ and BAT- subjects. ${ }^{* *} p=0.007$ using by one sample $t$-test, ${ }^{*} p$ $=0.03$ using Student's $t$-test. (D) Correlation of BAT volume with the change in supraclavicular skin body temperature using Pearson's $r$. The data are means and standard deviations. The dashed lines represent $95 \%$ confidence intervals.

anatomical locations of BAT (i.e., supraclavicular, peri-renal, mediastinal, and paravertebral areas). CE decreased the skin temperature of the supraclavicular area in the BAT- group only $\left(-1.8^{\circ} \mathrm{C}, 95 \% \mathrm{CI}:-2.9\right.$ to $-0.6, p=0.007$, Figure $\left.3 \mathrm{C}\right)$, while no significant change was noted in the BAT+ group. The cold-induced change in the supraclavicular skin temperature was significantly different between BAT + and BAT - subjects $\left(-1.4^{\circ} \mathrm{C}, 95 \% \mathrm{CI}:-2.6\right.$ to $\left.-0.2, p=0.03\right)$. The cold-induced change in supraclavicular temperature $(r=0.58, p=0.014)$ correlated with BAT volume (Figure 3D). No correlation was noted between muscle activity and the supraclavicular or trunk skin temperature during the last hour of CE (Table 2). Finally, BAT volume was significantly associated with supraclavicular $(p$ $=0.03$ ) and marginally associated with trunk skin temperature $(p=0.07)$ after adjustment for age and adiposity (Table 3 ). These data further demonstrate a significant role for human BAT in thermoregulation, where cold-induced BAT activation affects skin temperature in areas adjacent to the anatomical localization of BAT.

\section{Body Temperatures as Non-invasive Indices of BAT Activity}

Since the available methods to estimate BAT volume [e.g., $\mathrm{PET} / \mathrm{CT}$, magnetic resonance imaging (MRI), or infrared thermography] involve exposure to radiation and/or are costly and labor-intensive, we propose that changes in body core and skin temperatures during CE can be potentially used as surrogate markers of BAT activity. To further validate those indices as surrogate markers, we tested their correlation with BAT activity for the different durations of CE (Table 4). Change in core and supraclavicular temperatures were significantly correlated with BAT activity after 3-4 h of CE, respectively.

\section{BAT Activation and Cardiovascular Function in Response to CE}

Finally, we investigated the cold-induced changes in markers of cardiovascular function and cutaneous perfusion in BAT + and BAT - subjects. The average skin temperature (BAT-: $-3.5^{\circ} \mathrm{C}$, 95\% CI: -4.8 to $-2.1, p=0.001$ and $\mathrm{BAT}+:-3.2^{\circ} \mathrm{C}, 95 \% \mathrm{CI}$ : -3.7 to $-2.7, p<0.001$, Figure $4 \mathrm{~A}$ ) and distal skin temperature (BAT-: $-7.4^{\circ} \mathrm{C}, 95 \% \mathrm{CI}:-5.1$ to $-9.7, p<0.001$ and BAT+: $-6.8^{\circ} \mathrm{C}, 95 \% \mathrm{CI}:-8.9$ to $-4.8, p<0.001$, Figure $4 \mathrm{~B}$ ) significantly decreased in both groups. Moreover, both groups displayed a similar degree of peripheral vasoconstriction during CE (BAT-: $-9.9^{\circ} \mathrm{C}, 95 \% \mathrm{CI}:-11.0$ to $-7.9, p<0.001$ and $\mathrm{BAT}+:-9.5^{\circ} \mathrm{C}$, $95 \% \mathrm{CI}:-12.2$ to $-6.9, p<0.001$, Figure $4 \mathrm{C})$. Additionally, CE significantly decreased heart rate only in the BAT + group $(-2.5$ beats $/ \mathrm{min}, 95 \% \mathrm{CI}:-4.7$ to $-0.3 p=0.03$, Figure $4 \mathrm{D})$. We noted no significant differences in systolic blood pressure (Figure 4E), while diastolic blood pressure increased in both groups (BAT-: $11.75 \mathrm{mmHg}$, 95\% CI: 0.1-23.6, $p=0.052$ and BAT +: $8.2 \mathrm{mmHg}$, $95 \%$ CI: $1.0-15.4, p=0.03$, Figure $4 F)$.

\section{DISCUSSION}

The results of this study provide evidence of the physiological role of BAT in thermoregulation in people. BAT volume was a significant predictor of the cold-induced change in 
TABLE 3 | Multiple linear regression analysis.

\begin{tabular}{|c|c|c|c|c|c|c|c|c|}
\hline \multirow[t]{2}{*}{ Independent predictors } & \multicolumn{4}{|c|}{ Univariate analysis } & \multicolumn{4}{|c|}{ Multiple regression analysis } \\
\hline & Beta & St. Error & St. Beta & $p$-value & Beta & St. Error & St. Beta & $p$-value \\
\hline \multicolumn{9}{|c|}{ DEPENDENT VARIABLE: CHANGE IN CORE TEMPERATURE DURING THE $5 \mathrm{~h}$ OF COLD EXPOSURE } \\
\hline BAT volume ${ }^{a}$ & 0.244 & 0.056 & 0.784 & 0.001 & 0.254 & 0.08 & 0.79 & 0.01 \\
\hline Body fat \% & -0.013 & 0.009 & -0.398 & 0.159 & -0.005 & 0.007 & -0.15 & 0.534 \\
\hline Age & -0.008 & 0.004 & -0.481 & 0.08 & 0.002 & 0.005 & 0.13 & 0.641 \\
\hline \multicolumn{9}{|c|}{ DEPENDENT VARIABLE: CHANGE IN SUPRACLAVICULAR TEMPERATURE DURING THE $5 \mathrm{~h}$ OF COLD EXPOSURE } \\
\hline BAT volume ${ }^{a}$ & 0.870 & 0.301 & 0.599 & 0.011 & 1.048 & 0.430 & 0.721 & 0.030 \\
\hline Body fat \% & -0.058 & 0.037 & -0.373 & 0.140 & -0.029 & 0.040 & -0.191 & 0.475 \\
\hline Age & -0.021 & 0.019 & -0.278 & 0.279 & 0.024 & 0.023 & 0.319 & 0.319 \\
\hline \multicolumn{9}{|c|}{ DEPENDENT VARIABLE: CHANGE IN TRUNK TEMPERATURE DURING THE $5 \mathrm{~h}$ OF COLD EXPOSURE } \\
\hline BAT volume ${ }^{a}$ & 0.570 & 0.413 & 0.326 & 0.187 & 0.973 & 0.501 & 0.557 & 0.070 \\
\hline Body fat \% & -0.67 & 0.040 & -0.388 & 0.112 & -0.094 & 0.045 & -0.544 & 0.057 \\
\hline Age & 0.002 & 0.022 & 0.023 & 0.927 & 0.066 & 0.028 & 0.742 & 0.032 \\
\hline
\end{tabular}

${ }^{a} B A T$ volume was transformed to $\log _{10}[B A T$ volume $(m l)+1]$.

TABLE 4 | Indexes of brown adipose tissue volume and duration of cold exposure.

\begin{tabular}{|c|c|c|c|c|c|}
\hline Parameters & $1 \mathrm{~h}$ & $2 \mathrm{~h}$ & $3 h$ & $4 h$ & $5 \mathrm{~h}$ \\
\hline \multirow{2}{*}{$\begin{array}{l}\text { Change in core } \\
\text { temperature }\left({ }^{\circ} \mathrm{C}\right)\end{array}$} & $r=0.34$ & $r=0.37$ & $r=0.63$ & $r=0.67$ & $r=0.79$ \\
\hline & $p=0.24$ & $p=0.20$ & $p=0.016$ & $p=0.012$ & $p=0.001$ \\
\hline Change in & $r=0.42$ & $r=0.42$ & $r=0.45$ & $r=0.56$ & $r=0.584$ \\
\hline $\begin{array}{l}\text { supraclavicular skin } \\
\text { temperature }\left({ }^{\circ} \mathrm{C}\right)\end{array}$ & $p=0.1$ & $p=0.1$ & $p=0.1$ & $p=0.019$ & $p=0.014$ \\
\hline
\end{tabular}

BAT volume was transformed to $\log _{10}[B A T$ volume $(m l)+1]$. The correlation coefficients were calculated using Pearson's $r$. The bold values indicate statistically significant correlations.

core temperature, adding to the notion that BAT activation contributes to homeothermy. Moreover, having significant amounts of detectable BAT was associated with increased capacity to compensate for heat loss, as evidenced by the lower ambient CE temperature tolerated in the BAT + group without shivering. Finally, the significant correlation between the coldinduced change in core and supraclavicular temperature suggest those two measures as a potential surrogate markers of BAT activity.

The first line of evidence suggesting a physiological role of BAT in thermoregulation is the finding that the subjects in the BAT + group demonstrated different response in their core body temperature after $5 \mathrm{~h}$ of non-shivering CE compared to BAT - subjects. Namely, core body temperature significantly decreased in the BAT - group, but it remained unchanged in the $\mathrm{BAT}+$ group. BAT is strategically localized in close proximity to central vessels (carotid artery, brachiocephalic artery, epicardial coronary artery, cardiac veins, and others) (Sacks and Symonds, 2013), which increases the efficiency of heat transfer to core organs.

We did not find any significant differences between the two groups in the indices used to evaluate vasoconstriction/cutaneous skin perfusion. Heart rate decreased significantly in BAT+ subjects during CE, while systolic blood pressure was significantly elevated in the BAT + group and marginally elevated in BATsubjects. These results suggest that $\mathrm{BAT}+$ and $\mathrm{BAT}-$ subjects may have distinct cardiovascular responses to $\mathrm{CE}$.

Maintenance of core body temperature within a narrow range, despite the influence of external stimuli, is of vital importance to mammals (Mekjavic and Eiken, 2006). Early studies in rodents demonstrated that BAT temperature increases during $\mathrm{CE}$, providing direct evidence for the thermoregulatory role of BAT in mammals (Donhoffer et al., 1964). In the current study, the intensity of CE, which was higher in the BAT+ group, was titrated individually to induce maximal non-shivering thermogenesis. The small decrease in core temperature noted in the BAT- participants indicates the decreased ability of this group to keep the core temperature constant during prolonged CE. Should this decrease in body core temperature have continued, it would likely have resulted in shivering to prevent further decline. The magnitude of change in core temperature was strongly correlated with BAT volume, while the association of BAT with core temperature remained statistically significant after adjustment for age and adiposity. Muscle metabolic activity was not significantly correlated with body core temperature.

Having established a role for BAT in thermoregulation in adult humans, we tested the ability of core temperature and skin temperatures to predict BAT volume. The methods currently available to measure BAT volume and activity (PET/CT, MRI, infrared thermography, etc.) are expensive and involve exposure to radiation and/or require availability of specialized equipment. Therefore, surrogate measures of BAT volume using methods that are safer, easy to perform, and less expensive than those outlined above, could become useful research tools. BAT is primarily located in the supraclavicular, paravertebral, and, perirenal areas. We hypothesized that skin temperatures adjacent to BAT may provide low-cost, non-invasive surrogate markers of BAT activity. Consistent with our hypothesis, BAT volume significantly correlated with changes in core and supraclavicular skin temperature. In addition, BAT volume was marginally associated with the change in trunk temperature after adjustment for age and adiposity. Studies in young lean subjects and children 


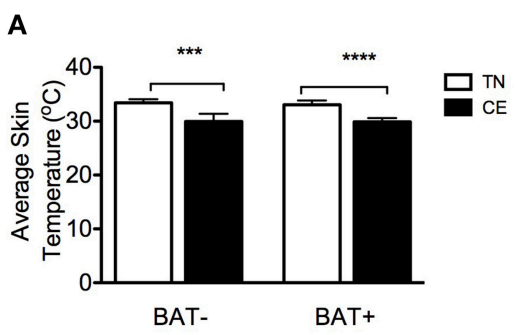

C

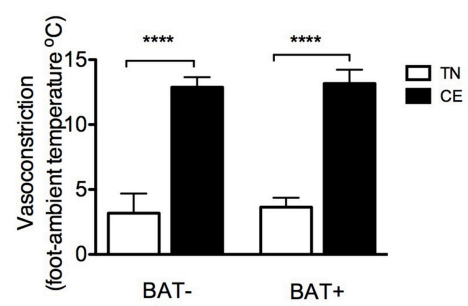

E

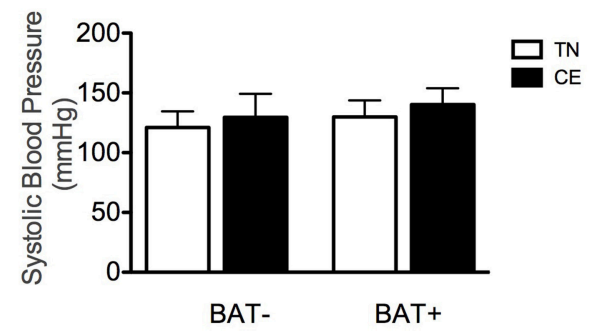

B

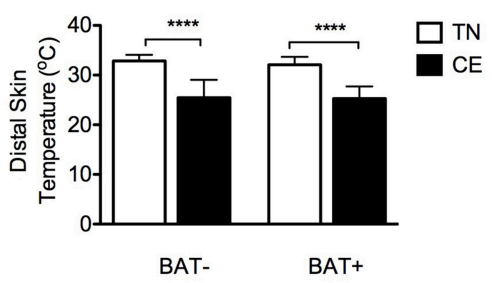

D

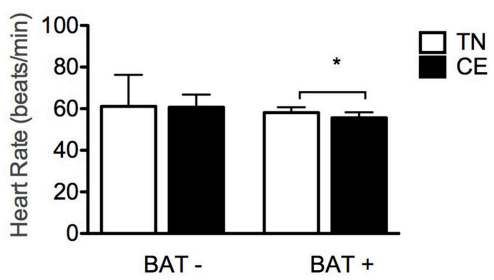

F

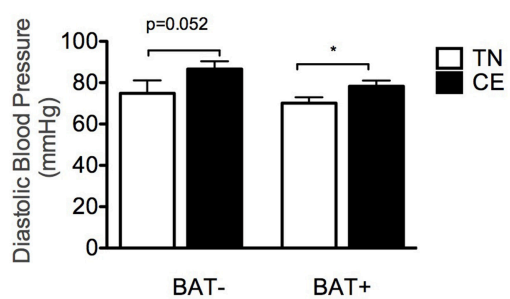

FIGURE 4 | Brown adipose tissue (BAT) activation, skin perfusion, and cardiovascular response to cold exposure (CE). (A) Average skin temperature in subjects with detectable BAT (BAT+) and without detectable BAT (BAT-) in thermoneutral (TN) conditions and at $5 \mathrm{~h}$ of CE. (B) Distal (hand, foot) skin temperature in BAT+ and BAT - subjects in TN conditions and after $5 \mathrm{~h}$ of CE. (C) Vasoconstriction/skin perfusion in BAT+ and BAT- subjects in TN conditions and at $5 \mathrm{~h}$ of CE. (D) Heart rate in BAT+ and BAT - subjects in TN conditions and at $5 \mathrm{~h}$ of CE. (E,F) Systolic (E) and diastolic (F) blood pressure in BAT+ and BAT - subjects in TN conditions and at $5 \mathrm{~h}$ of CE. Data are means and standard deviations. The data are means and SD. ${ }^{*} p<0.05,{ }^{* \star *} p=0.001,{ }^{* * \star *} p<0.001$ using paired $t$-test.

have proposed supraclavicular temperature (Symonds et al., 2012; Boon et al., 2014; van der Lans et al., 2016) and the gradient between the supraclavicular and the lateral upper chest temperatures (Jang et al., 2014) as surrogate measures of BAT activity. Here, we provide evidence that supraclavicular skin and core body temperatures can be used markers of BAT volume in a more diverse population when the other methods for the detection of BAT activity are not available or contraindicated.

Results from previous studies, in which BAT has not been measured support the link between temperature homeostasis with age and adiposity (Hayward and Keatinge, 1981; Kenney and Munce, 2003; Wijers et al., 2010). On the other hand, BAT activity has been inversely associated with age (Cypess et al., 2009; Yoneshiro et al., 2011) and adiposity (Saito et al., 2009; van Marken Lichtenbelt et al., 2009). Therefore, it is likely that BAT levels may at least partially explain this relationship between adiposity, aging, and temperature homeostasis. The results of this study have been statistically adjusted to account for a potential confounding effect of age and adiposity and they support the independent the role of BAT in thermoregulation in humans. Moreover, when we restricted our groups to subjects matched for age and adiposity the reported outcomes between the two groups remained the same further supporting our conclusions (data not shown).

Our results support the notion that BAT plays a role in thermoregulation by increasing heat production. BAT and adiposity are inversely correlated (van Marken Lichtenbelt et al., 2009). Furthermore, weight loss (Vijgen et al., 2012; Orava et al., 2013) and chronic CE (Yoneshiro et al., 2013) increase BAT and decrease body fat. We could thus speculate that a chronic positive energy balance that increases adiposity may lead to greater insulation and, potentially, underutilization of BAT for heat production. This will ultimately result in further weight gain and its related metabolic abnormalities (hyperlipidemia, insulin resistance, etc.).

Thermoregulation constitutes an important homeostatic mechanism, tightly linked to survival. This study provides evidence for the physiologically significant role of BAT in thermoregulation in people. Moreover, we propose two indices that can be used to estimate BAT volume when radiological approaches or other techniques are not available, and/or their use is contraindicated. Further research is needed to understand the 
role of human BAT in pathological conditions that cause a shift in core body temperature from the null zone (fever, anesthesia) and conditions that affect heat loss or production (e.g., burn injury).

\section{AUTHOR CONTRIBUTIONS}

Conception and design of the work: LS, EV, EB, MC, CP, and CY. Acquisition, analysis, or interpretation of data for the work: $\mathrm{MC}$, EV, EB, TC, CP, PA, CY, SL, NH, IM, FC, and LS. Drafting of the work or revising it critically for important intellectual content: MC, EV, EB, TC, CP, PA, CY, SL, NH, IM, FC, and LS. All authors have approved the final version of the manuscript and agree to be accountable for all aspects of the work in ensuring that questions related to the accuracy or integrity of any part of the work are appropriately investigated and resolved. All persons designated as authors qualify for authorship, and all those who qualify for authorship are listed.

\section{FUNDING}

This study was conducted with the support of the Institute for Translational Sciences at the University of Texas Medical Branch, supported in part by a Clinical and Translational Science Award (UL1TR000071) from the National Center for Advancing Translational Sciences, National Institutes of Health, the American Diabetes Association (1-14-TS-35 to LS), Shriners Hospitals for Children grants (84090 and 85310 to LS), the John Sealy Memorial Endowment Fund for Biomedical Research

\section{REFERENCES}

Blondin, D. P., Labbé, S. M., Tingelstad, H. C., Noll, C., Kunach, M., Phoenix, S., et al. (2014). Increased brown adipose tissue oxidative capacity in cold-acclimated humans. J. Clin. Endocrinol. Metab. 99, E438-E446. doi: 10.1210/jc.2013-3901

Boon, M. R., Bakker, L. E., van der Linden, R. A., Pereira Arias-Bouda, L., Smit, F., Verberne, H. J., et al. (2014). Supraclavicular skin temperature as a measure of $18 \mathrm{~F}-\mathrm{FDG}$ uptake by BAT in human subjects. PLoS ONE 9:e98822. doi: 10.1371/journal.pone.0098822

Cannon, B., and Nedergaard, J. (2004). Brown adipose tissue: function and physiological significance. Physiol. Rev. 84, 277-359. doi: 10.1152/physrev.00015.2003

Chondronikola, M., Volpi, E., Borsheim, E., Porter, C., Annamalai, P., Enerback, S., et al. (2014). Brown adipose tissue improves whole-body glucose homeostasis and insulin sensitivity in humans. Diabetes 63, 4089-4099. doi: 10.2337/db140746

Cypess, A. M., Lehman, S., Williams, G., Tal, I., Rodman, D., Goldfine, A. B., et al. (2009). Identification and importance of brown adipose tissue in adult humans. N. Engl. J. Med. 360, 1509-1517. doi: 10.1056/NEJMoa0810780

Davis, T. R. (1961). Chamber cold acclimatization in man. J. Appl. Physiol. 16, 1011-1015.

Dawkins, M. J., and Scopes, J. W. (1965). Non-shivering thermogenesis and brown adipose tissue in the human new-born infant. Nature 206, 201-202. doi: $10.1038 / 206201$ b0

de Dear, R. J., Brager, G., and Cooper, D. (1998). Developing an Adaptive Model of Thermal Comfort and Preference. Final Report on ASHRAE RP-884. ASHRAE, Atlanta, GA, USA.

de Deara, R. J., and Brager, G. S. (2002). Thermal comfort in naturally ventilated buildings: revisions to ASHRAE Standard 55. Energy Build. 34, 549-561. doi: 10.1016/S0378-7788(02)00005-1
(66992 to LS), the Claude Pepper Older Americans Independence Center (P30 AG024832 to EV), and the Sealy Center on Aging (grant to LS). MC was funded by the Onassis Foundation. SL is funded by a Canadian Institute of Health Research postdoctoral fellowship. CP was supported in part by a National Institute of Disability and Rehabilitation Research Postdoctoral Training Grant (H133P110012).

\section{ACKNOWLEDGMENTS}

The authors want to thank the study participants and personnel at the Institute of Translational Sciences Clinical Research Center, University of Texas Medical Branch. We thank Sarah Toombs Smith of the Sealy Center on Aging, University of Texas Medical Branch for editing the manuscript; Clark R. Andersen of the Department of Surgery, University of Texas Medical Branch for his help with the statistical analysis; Mohit Arora, Syed Habeebullah Husaini of the Sealy Center on Aging, University of Texas Medical Branch, Rene Przkora of the Department of Anesthesiology, University of Texas Medical Branch, and Lily Kwatampora and Alejandro Muñoz of the Department of Internal Medicine, University of Texas Medical Branch, for conducting the physical assessment of the participants; Rajesh Kumar of the Department of Nuclear Medicine, University of Texas Medical Branch, for performing the PET/CT scans; Cynthia Locklin, Carrie Barone, Aikaterini Illiadou, and Ginger Stuart of the Metabolism Unit, Shriners Hospital for Children for their administrative and technical support.

Donhoffer, S., Sardy, F., and Szegvari, G. (1964). Brown adipose tissue and thermoregulatory heat production in the rat. Nature 203, 765-766. doi: $10.1038 / 203765 b 0$

Hanssen, M. J., Hoeks, J., Brans, B., van der Lans, A. A., Schaart, G., van den Driessche, J. J., et al. (2015a). Short-term cold acclimation improves insulin sensitivity in patients with type 2 diabetes mellitus. Nat. Med. 21, 863-865. doi: 10.1038/nm.3891

Hanssen, M. J., van der Lans, A. A., Brans, B., Hoeks, J., Jardon, K. M., Schaart, G., et al. (2015b). Short-term cold acclimation recruits brown adipose tissue in obese humans. Diabetes. doi: 10.2337/db15-1372. [Epub ahead of print].

Hayward, M. G., and Keatinge, W. R. (1981). Roles of subcutaneous fat and thermoregulatory reflexes in determining ability to stabilize body temperature in water. J. Physiol. 320, 229-251. doi: 10.1113/jphysiol.1981.sp0 13946

ISO9886 (2004). Evaluation of Thermal Strain by Physiological Measurements. Geneva: International Standards Organization.

Ito, S., and Kuroshima, A. (1967). [Distribution of brown adipose tissue in Japanese new-born infants]. Nihon Seirigaku Zasshi 29, 660-661.

Jang, C., Jalapu, S., Thuzar, M., Law, P. W., Jeavons, S., Barclay, J. L., et al. (2014). Infrared thermography in the detection of brown adipose tissue in humans. Physiol. Rep. 2:e12167. doi: 10.14814/phy2.12167

Kenney, W. L., and Munce, T. A. (2003). Invited review: aging and human temperature regulation. J. Appl. Physiol. (1985) 95, 2598-2603. doi: 10.1152/japplphysiol.00202.2003

Lee, P., Smith, S., Linderman, J., Courville, A. B., Brychta, R. J., Dieckmann, W., et al. (2014). Temperature-acclimated brown adipose tissue modulates insulin sensitivity in humans. Diabetes 63, 3686-3698. doi: 10.2337/db1 4-0513

Mekjavic, I. B., and Eiken, O. (2006). Contribution of thermal and nonthermal factors to the regulation of body temperature in humans. J. Appl. Physiol. (1985) 100, 2065-2072. doi: 10.1152/japplphysiol.01118.2005 
Nedergaard, J., Bengtsson, T., and Cannon, B. (2007). Unexpected evidence for active brown adipose tissue in adult humans. Am. J. Physiol. Endocrinol. Metab. 293, E444-E452. doi: 10.1152/ajpendo.00691.2006

Nedergaard, J., Golozoubova, V., Matthias, A., Asadi, A., Jacobsson, A., and Cannon, B. (2001). UCP1: the only protein able to mediate adaptive nonshivering thermogenesis and metabolic inefficiency. Biochim. Biophys. Acta 1504, 82-106. doi: 10.1016/S0005-2728(00)00247-4

Orava, J., Nuutila, P., Noponen, T., Parkkola, R., Viljanen, T., Enerbäck, S., et al. (2013). Blunted metabolic responses to cold and insulin stimulation in brown adipose tissue of obese humans. Obesity 21, 2279-2287. doi: 10.1002/oby.20456

Ouellet, V., Labbé, S. M., Blondin, D. P., Phoenix, S., Guérin, B., Haman, F., et al. (2012). Brown adipose tissue oxidative metabolism contributes to energy expenditure during acute cold exposure in humans. J. Clin. Invest. 122, 545-552. doi: 10.1172/JCI60433

Ruiz, C. E., Weil, M. H., and Carlson, R. W. (1979). Treatment of circulatory shock with dopamine. Studies on survival. JAMA 242, 165-168. doi: 10.1001/jama.1979.03300020035022

Sacks, H., and Symonds, M. E. (2013). Anatomical locations of human brown adipose tissue: functional relevance and implications in obesity and type 2 diabetes. Diabetes 62, 1783-1790. doi: 10.2337/db12-1430

Saito, M., Okamatsu-Ogura, Y., Matsushita, M., Watanabe, K., Yoneshiro, T., Nio-Kobayashi, J., et al. (2009). High incidence of metabolically active brown adipose tissue in healthy adult humans: effects of cold exposure and adiposity. Diabetes 58, 1526-1531. doi: 10.2337/db09-0530

Silverman, W. A., Zamelis, A., Sinclair, J. C., and Agate, F. J. (1964). Warm nap of the newborn. Pediatrics 33, 984-987.

Symonds, M. E., Henderson, K., Elvidge, L., Bosman, C., Sharkey, D., Perkins, A. C., et al. (2012). Thermal imaging to assess age-related changes of skin temperature within the supraclavicular region co-locating with brown adipose tissue in healthy children. J. Pediatr. 161, 892-898. doi: 10.1016/j.jpeds.2012.04.056

van der Lans, A. A., Hoeks, J., Brans, B., Vijgen, G. H., Visser, M. G., Vosselman, M. J., et al. (2013). Cold acclimation recruits human brown fat and increases nonshivering thermogenesis. J. Clin. Invest. 123, 3395-3403. doi: 10.1172/JCI68993

van der Lans, A. A., Vosselman, M. J., Hanssen, M. J., Brans, B., and van Marken Lichtenbelt, W. D. (2016). Supraclavicular skin temperature and BAT activity in lean healthy adults. J. Physiol. Sci. 66, 77-83. doi: 10.1007/s12576-015-0398-z van Marken Lichtenbelt, W. D., Vanhommerig, J. W., Smulders, N. M., Drossaerts J. M., Kemerink, G. J., Bouvy, N. D., et al. (2009). Cold-activated brown adipose tissue in healthy men. N. Engl. J. Med. 360, 1500-1508. doi: 10.1056/NEJMoa0808718

Vijgen, G. H., Bouvy, N. D., Teule, G. J., Brans, B., Hoeks, J., Schrauwen, P., et al. (2012). Increase in brown adipose tissue activity after weight loss in morbidly obese subjects. J. Clin. Endocrinol. Metab. 97, E1229-E1233. doi: 10.1210/jc.2012-1289

Virtanen, K. A., Lidell, M. E., Orava, J., Heglind, M., Westergren, R., Niemi, T., et al. (2009). Functional brown adipose tissue in healthy adults. N. Engl. J. Med. 360, 1518-1525. doi: 10.1056/NEJMoa0808949

Wijers, S. L., Saris, W. H., and van Marken Lichtenbelt, W. D. (2010). Coldinduced adaptive thermogenesis in lean and obese. Obesity (Silver Spring) 18, 1092-1099. doi: 10.1038/oby.2010.74

Wijers, S. L., Schrauwen, P., van Baak, M. A., Saris, W. H., and van Marken Lichtenbelt, W. D. (2011). Beta-adrenergic receptor blockade does not inhibit cold-induced thermogenesis in humans: possible involvement of brown adipose tissue. J. Clin. Endocrinol. Metab. 96, E598-E605. doi: 10.1210/jc.20101957

Yoneshiro, T., Aita, S., Matsushita, M., Kayahara, T., Kameya, T., Kawai, Y., et al. (2013). Recruited brown adipose tissue as an antiobesity agent in humans. J. Clin. Invest. 123, 3404-3408. doi: 10.1172/JCI67803

Yoneshiro, T., Aita, S., Matsushita, M., Okamatsu-Ogura, Y., Kameya, T., Kawai, Y., et al. (2011). Age-related decrease in cold-activated brown adipose tissue and accumulation of body fat in healthy humans. Obesity (Silver Spring) 19, 1755-1760. doi: 10.1038/oby.2011.125

Conflict of Interest Statement: The authors declare that the research was conducted in the absence of any commercial or financial relationships that could be construed as a potential conflict of interest.

Copyright (C) 2016 Chondronikola, Volpi, Børsheim, Chao, Porter, Annamalai, Yfanti, Labbe, Hurren, Malagaris, Cesani and Sidossis. This is an open-access article distributed under the terms of the Creative Commons Attribution License (CC BY). The use, distribution or reproduction in other forums is permitted, provided the original author(s) or licensor are credited and that the original publication in this journal is cited, in accordance with accepted academic practice. No use, distribution or reproduction is permitted which does not comply with these terms. 